\title{
O MEDO DO DESEMPREGO E A(S) NOVA(S) ORGANIZAÇÕES DE TRABALHO
}

\section{Laura Marques Castelhano \\ Pontifícia Universidade Católica de São Paulo}

RESUMO: O objetivo deste artigo é discutir como o aumento do desemprego altera as relações entre o sujeito e a organização, intensificando o medo no ambiente de trabalho. Demonstra-se como o medo de perder o emprego, torna o trabalhador mais vulnerável e sujeito a formas de dominação e controle, e produz efeitos como o aumento do sofrimento, a neutralização da mobilização coletiva e o individualismo.

PALAVRAS-CHAVE: desemprego, organização, medo, dominação, sofrimento.

\section{THE FEAR OF THE UNEMPLOYMENT AND THE NEW CORPORATION}

ABSTRACT: The objective of this article is to discuss how the unemployment increase alters the relationship between the subject and the organization, intensifying the fear factor in the work environment. The study demonstrates how the fear of losing the job leads the worker to become more vulnerable and susceptible to forms of domination and control. This fear also produces effects such as the increase of suffering, the neutralization of the collective mobilization and the individualism.

KEY-WORDS:: unemployment, organization, fear, domination, suffering

"o medo de perder o emprego aumenta a dependência à empresa, intregando-se (o sujeito) à produção e silenciando a própria dor." (Barreto, 2000, p. 144).

As organizações, que são os alicerces da produtividade do capital, estruturam-se de forma a conduzir o processo de acumulação, incentivando mudanças que propiciem aumento de produtividade.

Nas organizações a racionalização das estruturas e das relações pessoais se dissemina afetando os modos de vida e de trabalho, desenvolvendo uma estrutura mais enxuta, e muito mais flexível em suas formas contratuais, do que as antigas estruturas agrícolas e/ou as industriais dos primeiros períodos da industrialização.

Deflagram-se várias transformações no processo produtivo, alterando-se aos modos de gestão e as relações dentro das organizações, afetando, segundo Guimarães (2002), tanto os 'sobreviventes' deste processo, quanto os que dele parecem estar sendo 'excluídos'.

"A situação se modificou por completo a partir do inicio dos anos 1990, quando a atividade industrial foi profundamente golpeada pela abertura do mercado: o desemprego disparou, aumentou enormemente a informalidade, o desassalariamento avançou." (LEITE, 2003, p.105).

Mas, se por um lado temos mudanças nas estruturas organizacionais, temos por outro, novas exigências feitas ao sujeito da organização, que será afetado em toda intensidade.

O sujeito reproduzirá o novo discurso da organização: deverá ter responsabilidade, autonomia e senso de cooperação. No entanto, isto poderá explodir em conflito, já que a realidade, desejo e intenção do sujeito são diferentes dos desejos, realidades, e intenções da empresa.

Por isso Pagès (1987) afirmou que a organização funciona como um sistema de mediação das contradições, que tem de um lado os trabalhadores e do outro a empresa. O sistema de mediação se coloca como a aliança entre as restrições da empresa e os privilégios aos indivíduos.

Para o autor, a organização permite ao individuo defender-se da angústia, propondo-lhe um sistema de defesa sólido, organizado e legitimado pela sociedade. Em contrapartida, exige do individuo sua colaboração com a manutenção do poder, tentando evitar ao sujeito afrontar suas contradições íntimas.

Essa ação mediadora encobre e oculta processos contraditórios, tentando antecipar e transformar as contradições, antes que elas se transformem em conflitos coletivos. Tudo se passa como se as contradições fossem constantemente 'retomadas' no momento em que elas poderiam desembocar num conflito aberto com a empresa. 
Na mesma linha de raciocínio, Schirato (2000), em sua pesquisa com trabalhadores demitidos, concluiu que não há outra forma de pensarmos a relação homem-organização, senão com base em sua contradição.

Pode-se pensar que as políticas positivas das empresas são formas de antecipação de conflitos. Políticas de altos salários, participação nos lucros e resultados, promessas de carreira ascendentes, prêmios - tudo isso a seu preço.

A compreensão das relações de poder e dos sistemas de dominação são importantes para compreender a relação do sujeito com a empresa. $\mathrm{O}$ desenvolvimento de uma dominação psicológica, onde o sujeito tende a assumir a organização como sendo dele, fazem parte desta compreensão.

No entanto, há algo maior nessa relação sujeito - organização, e no desenvolvimento das formas de controle e dominação que complementam essa interação: o medo. Este sempre se instala no psiquismo do sujeito como um sinal ao perigo, imposto pela lei e pela autoridade.

O medo sempre esteve presente no ambiente laboral. A empresa sempre foi um ambiente estressor. Por exemplo, Seligmann-Silva (1994) identificou quatro formas de controle presentes dentro das empresas que pesquisou. Em dois deles, o medo está presente como resposta:

1. Sobre os riscos: a omissão de informações sobre os riscos laborais à saúde reflete uma forma de exerção de controle;

2. Sobre as sanções: a desinformação sobre sanções causa medo, como, por exemplo, ser despedido "sem direito". Ter o nome incluído nas próximas listas funcionaria como uma poderosa pressão;

3. Sobre os direitos e deveres face à legislação: não existe, de forma sistemática, a divulgação dos direitos e deveres dos trabalhadores.

4. Sobre os critérios para pagamento por produção: o desconhecimento das regras e critérios, que poderia provocar um conflito, faz o sujeito não protestar contra a possibilidade de estar sendo enganado, exatamente pelo medo de perder o emprego. Há a exploração do fatalismo.

Mas, o aumento do desemprego estrutural e a propagação de suas conseqüências devastadoras amplificam o medo no ambiente de trabalho, deixando o trabalhador muito mais vulnerável, e em situação muito mais fragilizada.
Para Dejours (2003), o 'consentimento' da maioria das pessoas com a situação de desemprego e miséria tem origem no medo, na vergonha e na forma como marcamos as distâncias em relação aos excluídos do sistema, para nos protegermos e suportarmos o sofrimento sem perder a razão.

O medo e a angústia do trabalhador empregado é uma das piores conseqüências do desemprego.

O medo e a angústia agravam o sofrimento mental. À medida que diminui a segurança no emprego, o medo abre uma porta para o sofrimento. Quem sofre é o sujeito, e sofre dentro e fora da organização. O desempregado, excluído do mercado de trabalho, tem medo de não encontrar um novo emprego, e o empregado, que está dentro da organização, sofre com o medo e com as pressões que podem virar ameaças, e até mesmo desembocar em novas demissões.

Inúmeras pesquisas e estudos que investigam a saúde do trabalhador em seu ambiente de trabalho advertem: o maior medo de quem tem emprego hoje, é perdê-lo.

Em pesquisa realizada com trabalhadores fabris, afastados por distúrbios nervosos, SeligmannSilva (1994) observou as manifestações do desgaste mental no trabalho e identificou várias conexões entre a vida laboral e as condições gerais de vida. Dentre esses aspectos, o medo surgiu como fator importante de avaliação, já que a sanção mais temida por todos os funcionários afastados era a demissão.

Antunes (1995) aponta que uma das conseqüências das mudanças ocorridas no mundo do trabalho foi a criação de um novo tipo de trabalhador, mais flexibilizado, mas, em contrapartida, mais inseguro em seu emprego.

Para Merlo (2003), às exigências da organização do trabalho somam-se novas exigências e outro sofrimento, que advém do medo de não ser capaz de manter uma performance adequada no trabalho, nas novas formas de gestão "reestruturadas", por medo de serem punidos com a demissão.

Há décadas, o campo da Saúde Mental e Trabalho (SM\&T) desenvolve estudos contribuindo para a melhor compreensão da saúde do trabalhador. Apesar de toda polêmica e discordâncias, oriundas da impossibilidade do nexo causal doença / trabalho, constata-se a existência do sofrimento, mas não se identificam suas origens.

Mas, Barreto (2000) aponta que a impossibilidade de reconhecer o nexo causal da doença com o trabalho, faz com que o adoecido tenha que comprovar a sua doença e correlacioná-la ao seu trabalho. Sofrendo a partir daí, pressões e ameaças, sendo ridicularizado e humilhado, o sujeito chega, muitas vezes, a concordar com a demissão e ainda 
sentir-se culpado.

Todos esses problemas, provavelmente ocorrem por que o trabalho extrapola a atividade em si. Na relação com o sujeito, o trabalho invade e permeia todas as suas atividades e é determinado pela estrutura política, social e cultural, entrando na composição de sua identidade.

Por isso, uma situação de crise econômica e agravamento da insegurança, altera as relações no trabalho. Há uma relação entre o social e o trabalho, e o sujeito na organização será afetado por isso, aumentando seu medo e sofrimento. Para Merlo (2002), o medo é um dos sofrimentos mais importante provocados pelo trabalho.

As mudanças estruturais no trabalho agravaram as situações causadoras de medo. O medo do desemprego altera as reações já existentes e cria novas formas, podendo ocasionar maiores danos ao sofrimento físico e mental do trabalhador.

Mas, quais as conseqüências do medo mobilizado nas relações de trabalho para o sujeito?

Dejours (2003), em análise sobre o medo no ambiente organizacional, aponta que o medo deve ser sempre analisado em relação com os processos de demissões e precarização do trabalho. Compreende a relação dos fatores externos à estrutura do trabalho, como orientador de uma conduta interna, e propõe quatro efeitos principais para a mobilização do medo:

a) a intensificação do trabalho e o aumento do sofrimento subjetivo;

b) a neutralização da mobilização coletiva;

c) a emergência da estratégia coletiva do silêncio, cegueira e surdez, no sentido de "não perceber" o sofrimento e a injustiça infligidos a outrem;

d) o individualismo.

Abaixo, proponho uma discussão sobre essas questões levantadas por Dejours (2003):

\section{A INTENSIFICAÇÃO DO TRABALHO E}

\section{O AUMENTO DO SOFRIMENTO SUBJETIVO:} MEDO TRANSFORMADO EM PRODUTIVIDADE

Segnini (1999) aponta, em estudo com bancários em São Paulo, que o medo da perda do emprego, sempre presente em todas as entrevistas e nos debates em grupo, constitui-se em grande motivador para o trabalho, em tempos de discursos participacionistas.

A percepção dos trabalhadores é de que trabalham mais, percebendo salários relativamente menores, em comparação com os anos anteriores.

Nesse sentido, o medo é transformado em produtividade, já que se observa a intensificação do trabalho, tanto pela fusão de postos de trabalho, como pelas exigências decorrentes de programas de gestão, como por exemplo, de qualidade. Procuram a maximização dos resultados pela forma de dominação e controle que se faz pela organização, transformando medo em sujeição.

"O sentimento de insegurança quanto à manutenção de emprego também pode ser instrumentado." (SELIGMANN-SILVA, 1994, p.159).

O medo torna-se um poderoso instrumento de manipulação. E como aponta Freitas (1996), se a demissão é vista como um ato de punição, o medo é a garantia da sujeição do sujeito.

Ghisleni (2003) observou que com o medo do desemprego, os trabalhadores vêem-se em situação de não poder parar de trabalhar, mesmo que já tenham cumprido suas tarefas. Eles alegam que se a chefia percebe que estão parados, interpreta que estão fazendo "corpo mole", que estão com pouco trabalho, ou ainda, que querem ser demitidos.

Para Seligmann-Silva (1994), o medo surge como resultado de um sistema de dominação e controle existente dentro do ambiente de trabalho, e aponta a existência de dois tipos de dominação: a repressão explícita e a dominação sutil.

Segundo a autora, a dominação sutil apresenta-se de maneira muito mais perigosa. Domina a manipulação de sentimentos como o afeto, a gratidão e a provocação de sentimento de culpa, onde as exigências são criadas em nome de uma racionalidade tecnológica.

Nesse tipo de manipulação, muito comum dentro das empresas hoje, o medo não é da violência, embutida na repressão explícita, o medo é de perder o prestígio, de fracassar, de perder seu posto.

A nova gestão do trabalho, que "vende" a idéia de ser mais adaptada ao ser humano, administra agora sob um aparato mais abstrato, mexendo muito mais com a subjetividade do sujeito e exigindo do profissional mais responsabilidade, adaptabilidade e perfeição.

Numa 'super empresa' ou empresa hipermoderna $^{1}$, só existe lugar para 'super empregados', que devem ser 'super-homens': bonitos, felizes, altamente qualificados, que não cometem erros, enfim, perfeitos.

Atitudes como estas são divulgadas pela mídia especializada que molda, personifica e padroniza o "empregado perfeito".

$\mathrm{O}$ trabalhador precisa ser rápido, porque o tempo do dinheiro é rápido; bondoso e cooperativo com os outros, reprimindo qualquer atitude de hostilidade; além de servir e seguir exemplos, o que significa repetir o modelo e o discurso da excelência.

É a exigência da excelência. A busca impos- 
sível, que massacra os sujeitos dentro da empresa.

Segundo Pagès (1987), o medo de fracassar e de perder o amor do objeto amado está sempre presente. Estes medos coexistem com a culpabilidade, pois dificilmente o sujeito, estará à altura das exigências da organização e do ideal que se procura atingir.

Werner (2002), em sua pesquisa sobre a vivência subjetiva do trabalhador diante dos processos de reestruturação, aponta que a tendência das empresas de privilegiar o fator humano tem por trás a promessa de um ideal: a promessa de uma satisfação "narcísica" ao sujeito. Isso, de alguma maneira, faz com que o sujeito intensifique sua energia e volte todas as suas forças para a empresa.

Anna Pollet (apud ANTUNES, 2002), ao estudar a sistemática do 'team work' (prática de gerenciamento moderno, que visa a estrutura de times dentro das empresas, privilegiando o trabalho e as decisões em grupo), concluiu que houve, por parte dos trabalhadores, pouca aceitação das "novas técnicas", aumento da competição entre eles, além de uma resposta gerencial mais dura. O que a princípio deveria funcionar sem comandos rígidos por parte dos gestores, intensificou o trabalho, a competição e o ambiente tornou-se mais estressante. A autora chamou atenção para a compreensão de que as mudanças ocorrem muito mais no plano do discurso, do que na realidade do trabalho cotidiano.

Outra pesquisa, de Carol Stephenson, confirma o peso do desemprego e do contexto econômico depressivo como fatores que propiciam o 'envolvimento' dos trabalhadores com o projeto da empresa. (ANTUNES, 2002, p. 82).

$\mathrm{O}$ individuo nas organizações vive o sonho de onipotência e perfeição, e a empresa sabe lidar com essa fragilidade a seu favor. É o que ressalta Macedo (1992), ao estudar o impacto do desemprego:

"o medo do desemprego, principalmente

frente á sua generalização na sociedade, pode gerar no empregado sentimento de gratidão, flexibilidade, etc, por estar trabalhando, mesmo que tenha garantido apenas o aspecto de remuneração." (MACEDO, 1992, p.51).

\section{A NEUTRALIZAÇÃO DA MOBILIZAÇÃO COLETIVA}

Uma das conseqüências dos fatores já comentados anteriormente, o medo mobilizador da produtividade, e o que discutirei no próximo item (a instrumentalização do individualismo), é o enfraquecimento da ação da classe trabalhadora.

Mattos (1998), ao analisar as características recentes da ação sindical no Brasil, coloca que um novo quadro de relações de trabalho, impulsionado pelo processo de reestruturação produtiva, flexibiliza os acordos, já que a última coisa que o trabalhador quer é correr o risco de entrar em conflito com seu empregador.

Nesse sentido, o medo de perder o emprego está implícito nessa relação. Assim, o medo traz, como conseqüência, o enfraquecimento da ação sindical.

É inegável que a situação de desemprego crescente é um obstáculo real à retomada das mobilizações sindicais, afinal, os sindicatos enfrentam hoje um esvaziamento dos seus quadros. Tanto pelo aumento do número de demitidos que deixam a categoria, como pelo esfriamento na disposição de luta dos trabalhadores diante do temor das demissões.

Alves (1999) coloca que o toyotismo buscou o consentimento ativo da subjetividade do "trabalho vivo", e passou a constituir-se através da síndrome do medo.

Para o autor, a precarização que se disseminou nos anos 90 no Brasil e que atingiu o "núcleo moderno" da implicação assalariada, catalisando a síndrome do medo, tornou-se perceptível não apenas através do crescimento do desemprego em massa, mas, principalmente, pela tendência contínua de precarização do estatuto salarial da força de trabalho no Brasil.

Como resultado de uma flexibilização das leis e proteções, a organização passa a não ser mais o ambiente seguro onde se passará o resto de sua vida ativa, até sua aposentadoria. Não há mais garantias, nem mesmo no mais seguro dos lugares.

O sujeito que, dentro da organização assiste a diversas demissões, vê vários de seus colegas serem mandados embora e que tem medo de ser a próxima vítima, sabe que a falta de proteção é uma das causas de sua angústia.

É 'atemorizante', pois o mercado é volátil. Histórias de desemprego de longa duração e de situações em que o trabalhador não consegue mais voltar para o mercado formal se repetem. E mais, aquele que consegue voltar ao mercado formal tem até mais medo, porque já conhece as conseqüências do desemprego.

"A situação de desempregado é compreendida através da experiência como empregado." (TITTONI, 1999, p.99).

\section{A EMERGÊNCIA DA ESTRATÉGIA COLETIVA DO} SILÊNCIO, CEGUEIRA E SURDEZ, NO SENTIDO DE "NÃO PERCEBER" O SOFRIMENTO E A INJUSTIÇA INFLIGIDOS A OUTREM

"Quando o medo atinge um nível muito alto e perdura por tempo prolongado, sem que o trabalhador consiga detectar sua fonte, ocorre uma evolução no siste- 
Castelhano, L.M. "O medo do desemprego e a(s) nova(s) organizações de trabalho"

ma e há um envolvimento maior, onde o organismo, como um todo, reage manifestando um quadro de angústia, extrema irritabilidade e depressão. A tensão interna aumenta tanto, que o indivíduo necessita manifestar seu descontentamento e descompasso." (SHERAFAT, 2002, p. 13).

Para Werner (2002), é possível questionar por que os trabalhadores não têm conseguido se organizar coletivamente na atualidade, como fizeram em outros momentos históricos.

Diversos autores se referem à inibição dos trabalhadores na manifestação da sua inconformidade por medo de perder o emprego, ou por "vergonha" de demonstrar que sofrem e reclamar de condições inumanas de trabalho. (DEJOURS, 2003; BÁRBARA,1997; GRISCI, 1999).

Na organização onde é o medo que impera, os boatos que precedem as demissões são os grandes geradores de angústia. E o silencio é a forma fatalista com a qual as pessoas vivenciam e enfrentam o processo de demissão.

Na verificação da trajetória profissional e subjetiva de ex-bancários que aderiram a programas de demissão (PDV - Programa de Demissão Voluntária), os autores, Silva (2000) e Calderon (2000) concluíram, em pesquisas diferentes, que o medo e a ansiedade foram utilizadas como instrumentos de pressão para a adesão ao programa de demissão. Nestes casos, o medo ganha dimensões coletivas, provocando defesas como o individualismo, competitividade e indiferença em relação aos sofrimentos psíquicos sofridos.

A raiva despertada pelos ataques à dignidade tende a ser reprimida, e muitas vezes ressurge, deslocada para o ambiente familiar ou através de distúrbios psicossomáticos:

"O temor de perder o emprego e a necessidade de garantir a convivência estavam subjacentes a estas dinâmicas, voltadas para a repressão e para o ocultamento da raiva.." (SELIGMAN, 1994, p 165).

Barreto (2000), ao divulgar a existência do assédio moral, caracterizado pela humilhação sofrida por trabalhadores adoecidos, apontou que a omissão dos sintomas da doença é uma pratica comum entre os trabalhadores, que não falam sobre sua doença por medo perder o emprego.

O medo aparece como fator, além de produtividade, também de submissão e omissão:

"por medo, passam a produzir mais do que as suas forças, ocultando suas queixas e evitando, simultaneamente, serem humilhados e demitidos." (BARRETO, 2000, p. 228).
O INDIVIDUALISMO:

\section{E O AGRAVAMENTO DA COMPETIÇÃO}

A nova organização exige um novo trabalhador, que deverá possuir novas características. O individualismo é uma delas. Constituindo-se como uma das respostas da mudança nas organizações, o individualismo marca uma nova forma de relacionamento dentro da empresa.

O medo muda as relações. Diante dele, cada individuo deverá se preocupar com a sua segurança, rompendo com os laços emocionais, exaltando o individualismo e aumentando a competição dentro da empresa.

O aumento da competitividade dentro das empresas é tido como expressão do desemprego. Para Werner (2002), o inimigo na nova organização é o colega ao lado, pois é tal a competição provocada por essas propostas individualistas, que o colega de trabalho passa a ser uma ameaça ao seu emprego.

Para Freud (1921), quando os laços mútuos entre os sujeitos do grupo deixam de existir, liberando um medo gigantesco e insensato, cada indivíduo passa a se preocupar apenas consigo próprio, sem qualquer consideração pelos outros. Nesse sentido, "o medo tornou-se grande a ponto de poder desprezar todos os laços e todos os sentimentos de consideração pelos outros." (FREUD 1921, p. 122).

O sujeito está mais sozinho do que nunca. Está desamparado, e não vê outra forma de assegurarse, se não pela sujeição às exigências da empresa.

Pagès (1987) coloca que o ambiente de competição desenfreado que se instala na organização faz com que o indivíduo fique isolado. Este indivíduo está condenado a vencer, pois é o meio de ser reconhecido e de ser amado. Coloca a carreira como o elemento central de sua relação com a organização.

Por isso, o individualismo é marcado pela auto-exigência e pela intensificação de sua responsabilidade, que segundo Antunes (1995), são os conceitos básicos na implementação do novo procedimento flexível na organização do trabalho.

Sherafat (2002) revela em seu estudo que, em geral, a falta de confiança gera muito medo e insegurança para os funcionários. Ele observa que a falta de relacionamento honesto e sincero causa muitos transtornos para todos.

A organização estimula o individualismo. Segundo Segnini (1999), os salários são estruturados de modo a reforçar esse processo, que somado ao medo do desemprego, promove índices de produtividade elevados.

Por isso, diante de diversas tensões o medo de ser mandado embora é o que permeia a vida dos trabalhadores.

Acrescento às idéias de Dejours (2003) dois 
pontos importantes que devem ser levados em conta e melhor estudados, quando falamos do medo de perder o emprego:

1. A imagem negativa que possui o desempregado em nossa sociedade

2. A historia de vida e profissional do sujeito

Refletir sobre o problema do desemprego e suas conseqüências, é necessário e urgente. Nossa postura não deve ser de quem olha o problema de fora, mas sim, de quem faz parte dele e pode contribuir para um avanço, que privilegia o bem estar do sujeito e não a propagação de seu sofrimento.

“(...) a indiferença pelo sofrimento psíquico dos que trabalham abriu caminho, portanto, à tolerância social para com o sofrimento dos desempregados." (Dejours, 2003, p.41).

\section{NOTAS}

${ }^{1}$ Termo utilizado por Max Pagés em "O poder das Organizações" (1987).

\section{REFERÊNCIAS:}

ALVES, Giovanni. Trabalho e sindicalismo no Brasil: um balanço crítico da 'década neoliberal (1990-2000)'. Rev. Sociologia e Política, Curitiba, n.19, pp.71-94, 1999.

ANTUNES, Ricardo. Adeus ao trabalho: ensaios sobre a metamorfose e a centralidade do mundo do trabalho. São Paulo: Cortez. 1995.

ANTUNES, Ricardo. Os sentidos do Trabalho. São Paulo: Boitempo. 2002.

BÁRBARA, Maristela. Reestruturação produtiva, qualificação, requalificação e desemprego: percepção e sofrimento do trabalhador. Trabalho de Conclusão de Curso, Departamento de Psicologia, da Pontifícia Universidade Católica de São Paulo. 1997.

BARRETO, Margarida Maria Silveira. Uma jornada de humilhações. Dissertação de Mestrado do Departamento de Psicologia Social, da Pontifícia Universidade Católica de São Paulo. 2000.

CALDERON, Regina do Carmo dos Santos. Desemprego e subjetividade; um estudo sobre programas de demissão voluntária. Dissertação de Mestrado, do Departamento de Psicologia, da Universidade São Marcos de São Paulo. 2000.

DEJOURS, Christophe. A Banalização da Injustiça Social. Tradutor: Luiz Alberto Monjardim. Rio de Janeiro: Editora FGV. 2003.
FREITAS, Lenita de Azeredo. E uma carreira profissional sólida se desmancha no ar: um estudo psicossocial da identidade. Dissertação de Mestrado. do Departamento de Psicologia Social, da Pontifícia Universidade Católica de São Paulo. 1996.

FREUD, Sigmund. Psicologia de Grupo e a Análise do Ego. Ed. Standard Brasileira das Obras Psicológicas Completas. Rio de Janeiro, Imago, $2^{\circ}$ Ed., Vol. XVIII,1921.

GHISLENI, Ângela. Corpos Ressentidos: Trabalho Contemporâneo, Subjetividade e Patologias por Hipersolicitação. Dissertação de Mestrado, Departamento de Psicologia e Institucional, da Universidade Federal do Rio Grande do Sul. 2003.

GRISCI, Carmem. Trabalho, tempo e subjetividade: impactos da reestruturação produtiva e o papel da psicologia nas organizações. Psicologia: Ciência e Profissão, São Paulo, n.19, pp. 2-13. 1999.

GUIMARÃES, Nadya. Por uma sociologia do desemprego. Rev. bras. Ci. Soc., São Paulo, vol.17, no.50, pp.104-121. 2002.

LEITE, Marcia de Paula. Trabalho e sociedade em transformação: mudanças produtivas e atores sociais. São Paulo: Fundação Perseu Abramo. 2003.

MACEDO, Lucinda. Desemprego e suas relações com a identidade: depoimentos. Dissertação de Mestrado. Departamento de Psicologia Social, da Pontifícia Universidade Católica de São Paulo. 1992.

MATTOS, Marcelo. Os Sindicatos e o desemprego no Brasil. CEAP. São Paulo, vol.15, no.1, pp. 12-25. 1998.

MERLO, Álvaro Roberto Crespo et al. O trabalho entre prazer, sofrimento e adoecimento: a realidade dos portadores de lesões por esforços repetitivos. Psicol. Soc. São Paulo, vol.15, no.1, pp. 117-136. 2003.

MERLO, Álvaro Roberto Crespo. Psicodinâmica do Trabalho. In: CODO, Wanderley, (org). Saúde mental e trabalho: Leituras. Rio de Janeiro: Ed Vozes. 2002.

PAGÈS, Max. O Poder das Organizações: a dominação das multinacionais sobre os indivíduos. São Paulo: Atlas,1987.

SCHIRATO, Maria Aparecida. O Feitiço das Organizações. São Paulo: Ed. Atlas. 2000.

SEGNINI, Liliana. Reestruturação nos Bancos no Bra- 
sil: Desemprego, sub contratação e intensificação do trabalho. Educ. Soc, Campinas, v.20, n.67, pp.183209. 1999.

SELIGMANN-SILVA, Edith. Desgaste Mental do Trabalho. São Paulo: Cortez Editora. 1994.

SHERAFAT, Felora. Produtividade na Ótica do Trabalhador: uma Análise dos aspectos que afetam o desempenho, criatividade e auto-estima dos funcionários no ambiente de trabalho. Dissertação de Mestrado, Departamento de Engenharia de Produção e Sistemas, da Universidade Federal de Santa Catarina. 2002.

SILVA, Eduardo. Demissões (in) voluntárias e subjetividade . Dissertação de Mestrado. Departamento de Psicologia Social, da UNICAMP. 2000.

TITTONI, Jaqueline. Trabalho e sujeição: trajetórias e experiências de trabalhadores demitidos no setor petroquímico. Tese de doutorado, Departamento de Sociologia, da Universidade Federal do Rio Grande do Sul. 1999.

WERNER, MárciaO processo de implantação da reestruturação produtiva: experiências e vivências dos trabalhadores: um estudo de caso. Dissertação de Mestrado. Departamento de Psicologia Social e Institucional da Universidade Federal do Rio Grande do Sul. . 2002.

Laura Marques Castelhano é mestranda do Programa de Psicologia Social PUC SP, bolsista CNPQ. O endereço eletrônico da autora é: lauracastelhano@uol.com.br

\section{Laura Marques Castelhano}

$O$ medo de desemprego e

a(s) nova(s) organizações do trabalho.

Recebido: 20/12/2004

$1^{\text {a }}$ revisão: 22/03/2005

Aceite final: 25/04/2005 